\title{
Structural Regulation of Methodological Management Approaches and Applied Reengineering Tools for Enterprises-Developers in Construction
}

\author{
Galyna Ryzhakova ${ }^{1}$, Vadym Pokolenko ${ }^{1}$, Oksana Malykhina ${ }^{1}$, Kostiantyn Predun ${ }^{2}$ and Nina Petrukha ${ }^{1}$ \\ ${ }^{1}$ Department of Management in Construction, Kyiv National University of Construction and Architecture, \\ Ukraine, Galyna_Ryzhakova@ukr.net \\ ${ }^{2}$ Department of Heat and Gas Supply and Ventilation, Kyiv National University of Construction and Architecture, \\ Ukraine, kmb_knuba@ukr.net
}

\begin{abstract}
The article discusses the problem of reengineering methodological approaches and applied tools to improve the activities of enterprises-developers in construction (EDC) as leading stakeholders of civil engineering. This study is dedicated to the development and application of structural regulation for EDC. Such approach is the starting point for the formation of a portfolio management system development projects. According to the chosen EDC strategy, the main target indicators are approved, taking into account the stage of EDC development, business model, market trends, as well as a number of other factors, such indicators may include: financial stability ratios, the level of financial leverage of EDC, liquidity ratios, profitability ratios. The methodology and applied tools have been adapted to the needs of EDC operation in the business environment of commercial housing projects, where the interaction of the developer with the asset management company is mandatory. It is proposed to carry out such interaction in the format of temporary on-site structures for the administration of investment and construction projects. The practical value of the results is that the management of development companies provided clearly formalized tools for organizing, operating and adjusting the operating system EDC, which allows the developer to successfully implement a growth strategy in the selected segment of development services administration of investment and construction projects.
\end{abstract}

Key words: reengineering, enterprises-developers in construction, stakeholders, development company, civil engineering.

\section{INTRODUCTION}

The functioning of the investment market of Ukraine is one of the main indicators of the state of the economy as a whole and a catalyst for its development, especially in the field of development in the construction industry. It is worth noting that until recently, investments in real estate were considered one of the most profitable, so in the transformational economy of Ukraine emerged and began to actively develop new investment entities. These are real estate investment companies that are considered to be an effective tool for intensifying the investment process. However, with the unfolding of the global financial crisis, real estate investments have not only lost their investment attractiveness, but also in the post-crisis period continue to be the most risky type of business.

The main task of developers is to overcome the main problems that arise during the implementation of projects for the construction and management of real estate: violation of the terms of construction and payback; deviation from the planned level of profitability; lack of funds for the implementation of development projects, etc. One of the tools for solving such problems is the introduction of an objectively developed system methodology for restructuring the activities of development companies and methods for evaluating development projects as integral parts of the investment decision-making process. The following outstanding foreign and domestic scientists have made a significant contribution to the theoretical substantiation and practical development of paradigms of development management, among which: C. Barltrop, J.B. Barney, C. Dietz, Peter F. Drucker, Robert S. Kaplan, James Brian Quinn.

Most authors [1-5] believe that EDC should be considered primarily a legal entity that provides paid services in the field of real estate development projects. However, not all authors agree that the enterprises-developer can participate with their own funds in the project. Some experts [6-8] describe such entities directly carry out the construction of real estate, etc; others consider the main activity of the EDC to increase the value of real estate.

Within the framework of our research it is necessary to pay attention to the economic nature of the EDC. The process of creating a real estate object is directly related to the necessary condition for ensuring the profitability of investors, in which the EDC is a key player by developing a mechanism for converting investment funds into real estate with further increase in its value. At first glance, it may seem that a EDC 
operates exclusively with investment funds, so the need for their placement is primary, and the search for the object of investment is secondary in importance. However, given that development companies arise as a result of combining experience with the tools of real estate, construction and financial companies, their use of their own resources to create real estate in accordance with the main stages of its implementation [9-11].

Among the functions of developers, domestic scientists [12-15] distinguish the issuance of permits in local authorities (instructions on the project, investment contract, technical passport, obtaining approvals and permits).

In particular, researchers [16-18] note that some development projects are not implemented only because local authorities do not allow the construction of real estate in the desired area for investors due to legal, environmental or social restrictions, and in addition, excessive complicated and lengthy process of approval of project documentation, the implementation of which not every investor can agree on the lack of time and opportunities to address such issues;

Design management (formation of a group of designers, management of the preparation of the draft project and feasibility study, management at the stage of working design) is the involvement of an effective staff team. In particular, Western scientists are of the opinion that without well-trained staff the implementation of a development project is almost impossible [19].

It is difficult to disagree with this, because indeed a team of professionals is one of the key factors in the project. Usually developers have a well-established database of employees, which allows you to quickly recruit teams of specialists to implement a development project [20].

- construction management (conducting tenders among construction contractors, construction management, commissioning of the facility);

- attraction of external credit and investment funds (development of investment strategy of the project, structure of financing of the project, agreements for signing between the company and financial institutions);

- marketing of real estate (development of marketing concept and strategy, advertising, development of a standard lease or sale agreement and negotiations with potential customers) [21].

Therefore, controversy is possible here, because other scientists [22, 23] consider it wrong to involve the development of contracts and negotiations with potential tenants or buyers in the marketing function of the DC. In their opinion, such a function should be allocated separately as a function of the implementation of a developed real estate object. It is also worth distinguishing the function of returning loans to investors and loans to commercial banks [24].
The interaction of development companies with other participants in the real estate market should be considered as a project interaction of the main actors in the real estate market, because without them it is impossible to implement a development project. Government agencies that regulate the real estate market are one of the main stakeholders in the process of implementing a development project, because it is in these institutions that the developer receives permission to build real estate.

It should be noted that the procedures for registration and obtaining permits have been gradually simplified over the last 10 years. This is evidenced by the rating of Doing Business. The rating makes it possible to assess the ease of doing business on ten key indicators and allows you to compare countries.

The places occupied by Ukraine in the Doing Business rankings in the period 2006-2020 are shown in Figure 1.

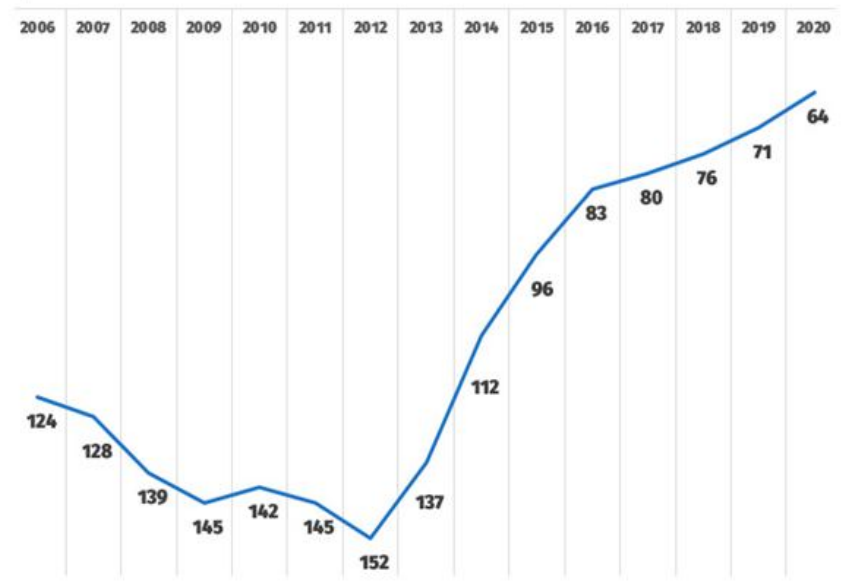

Figure 1: Diagram of Ukraine in the Doing Business rankings in the period 2006-2020 [24]

Some scholars [25] distinguish the following set of special functions of the development organization: the proper execution of the initial permits in the municipal authorities; construction management; attraction of external credit and investment funds; real estate marketing.

It can be seen that these functions are performed by development organizations in the case when they are the initiators of development projects.

Already today we can say that in the future the leading position in investment and construction activities in the creation of real estate will still belong to developers, as is done in the West.

Figure 2 shows comparison of the main organizational forms of civil engineering management in Ukraine and USA. 


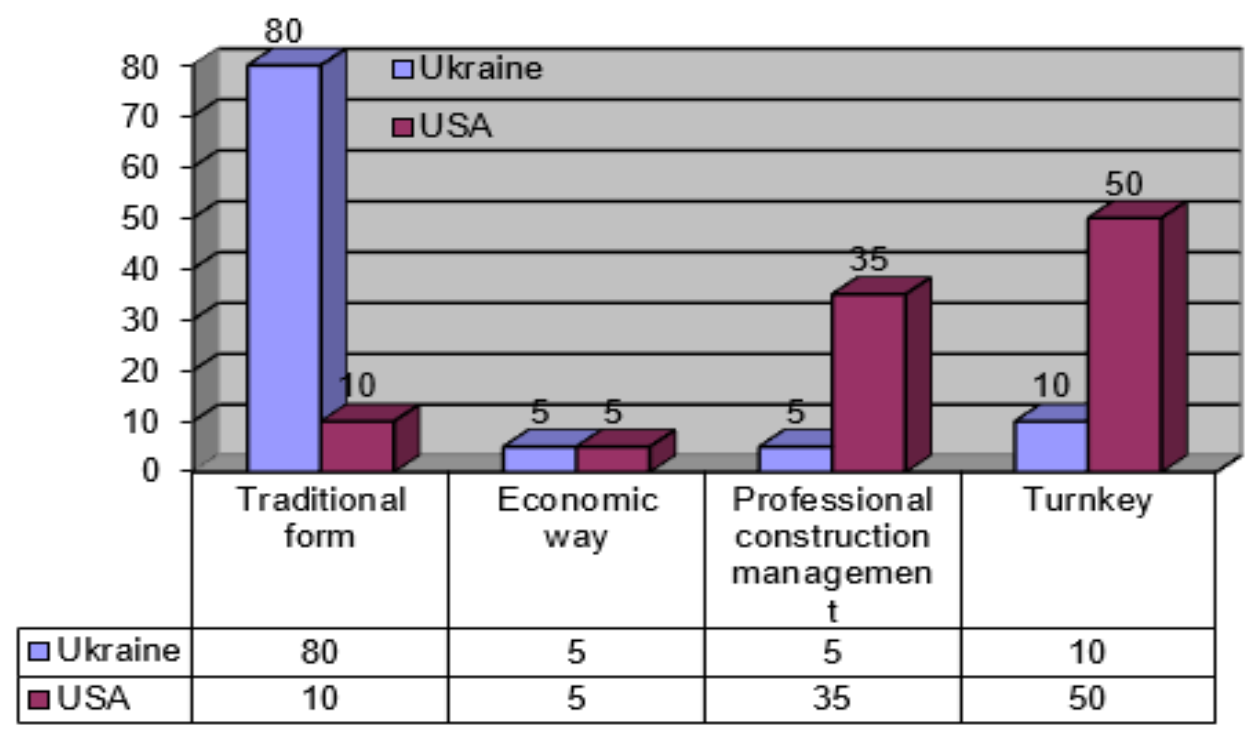

Figure 2: Comparison of the main organizational forms of civil engineering management in Ukraine and USA

The activities of enterprises-developers of civil engineering management in this case can be carried out in two forms, shown in Figure 2:

1) Professional construction management;

2) Turnkey construction.

In general, it can be argued that the development form of management in the investment and construction sector in Ukraine is used more than an order of magnitude less than in foreign practice. The big difference in the levels of use of the developer form of creation and development of real estate in Ukraine and United States should be explained by two most important reasons:

1) on the one hand, this is due to the fact that market forms of activity in Ukraine have been used not so long ago;

2) another, no less important reason is that Ukraine has not yet developed the forms of market infrastructure that contribute to the development.

\section{TOOLS AND METHODOLOGY}

Research in this area has established that the actual model of the activities of enterprises-developers in construction as the leading stakeholders in civil construction can be represented in the form of the scheme in Figure 3.

Among the known methodological approaches, very few of them pay attention to the role of external processes in the enterprise-developer in construction, and focus mainly on internal processes and their reengineering. There may be problems at the stage of implementation of the reengineering, when the system of internal processes can be balanced, but this system will not be able to adapt to the external market environment due to separation from real market processes. Therefore, it should be noted the significant role of monitoring external processes in their applied reengineering tools for enterprises-developers in construction.

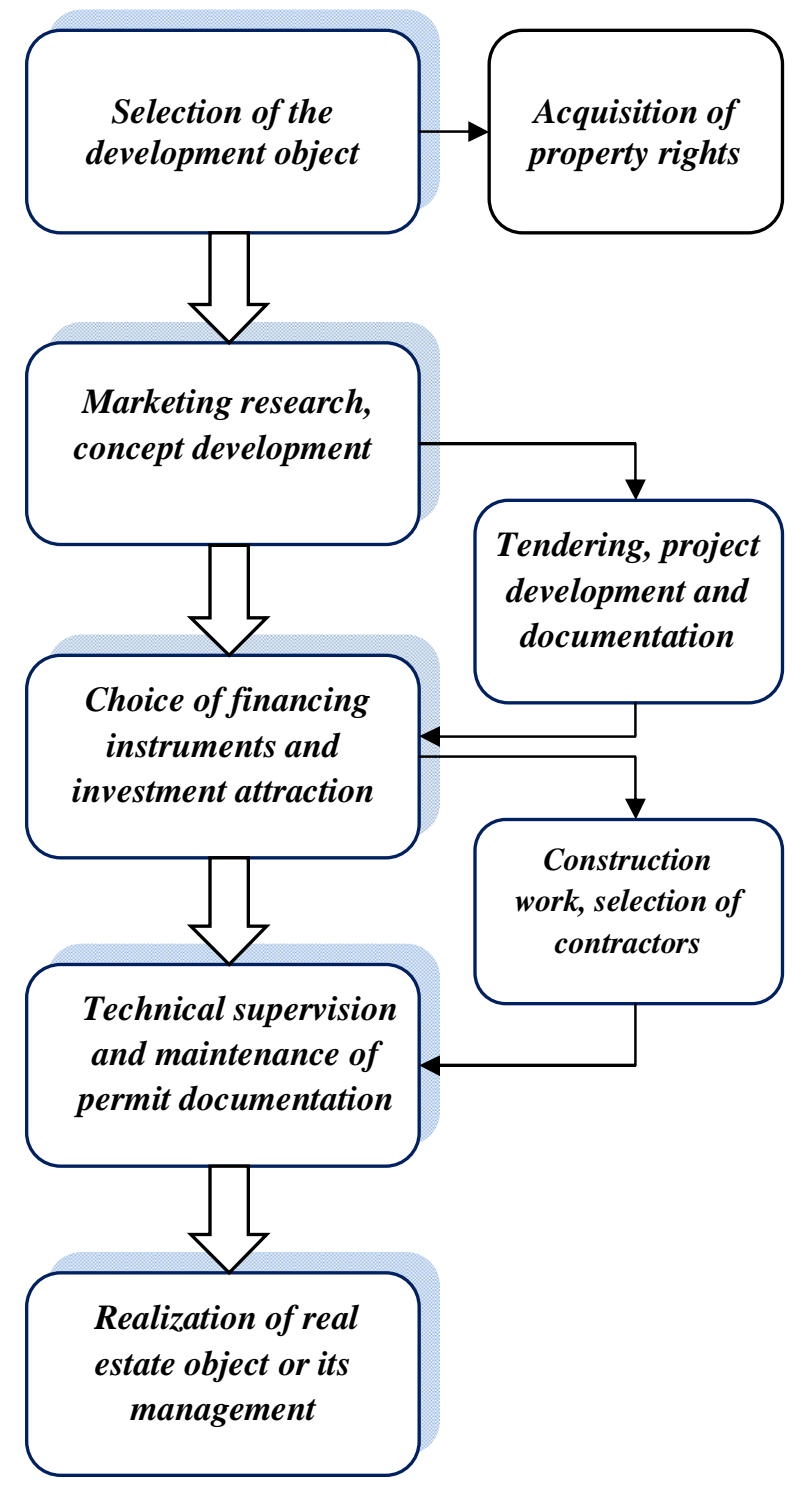

Figure 3: Model of enterprise-developer in construction 
Galyna Ryzhakova et al., International Journal of Emerging Trends in Engineering Research, 8(10), October 2020, 7560 - 7567

In addition to the mentioned functions in accordance with the scheme in Figure 3, the involvement of development companies in the implementation of the idea of a real estate development project has the following advantages:

- providing the investor of the project with the opportunity to avoid the need to create and maintain its own customer service to perform project management functions;

- formation of project strategy and terms of reference;

- ensuring control over the development of the project and construction program;

- ensuring control of optimization or minimization of the project budget;

- assistance in reducing construction time;

- ensuring quality control of construction;

- ensuring maximum financial efficiency of the project; protection of investors' interests before the contractor, designers, consultants, government agencies;

- avoiding a situation where the contractor, using the lack of professional experience of the investor, traditionally tries to either increase the budget (due to additional works) or reduce its own costs due to low quality materials and works, resulting in increased estimated cost of the object;

- ensuring compliance with the investment characteristics of real estate (the cost of services for the operation of the building and the possible income of the owner from the lease of the object);

- reducing the level of risks of insufficient liquidity, avoiding a decrease in profitability and property damage;

- ensuring compliance with the balance between the cost of maintaining the property and the income received as a result of sound management;

- elimination at the design stage of the discrepancy between the class of the building and the planned engineering infrastructure, timely changes to the project, which will allow the owner not only to save money on equipment, but also reduce the cost of its further operation, as to eliminate such discrepancies almost impossible.

Accordingly, the project portfolio management of the developer in construction will have three levels:

-Project portfolio management (strategic management)

-Production program management (statistical management)

-Investment and construction project management (operational management).

At the same time, effective operational management of the portfolio of construction EDC projects requires effective organization of two main business processes is the process of replenishment of the project portfolio and the process of balancing and portfolio management. Based on the object of study, we will primarily study the process of selecting projects for the project portfolio and the formation of the production program with the provision of the process of further operational management of this set of projects.

The main theory that describes the methodology of investment portfolio formation is Markowitz theory, according to which the investor chooses an investment portfolio, analyzing the indicators of risk and return. Figure 5 shows modified portfolio Markowitz model for enterprises-developers in construction.

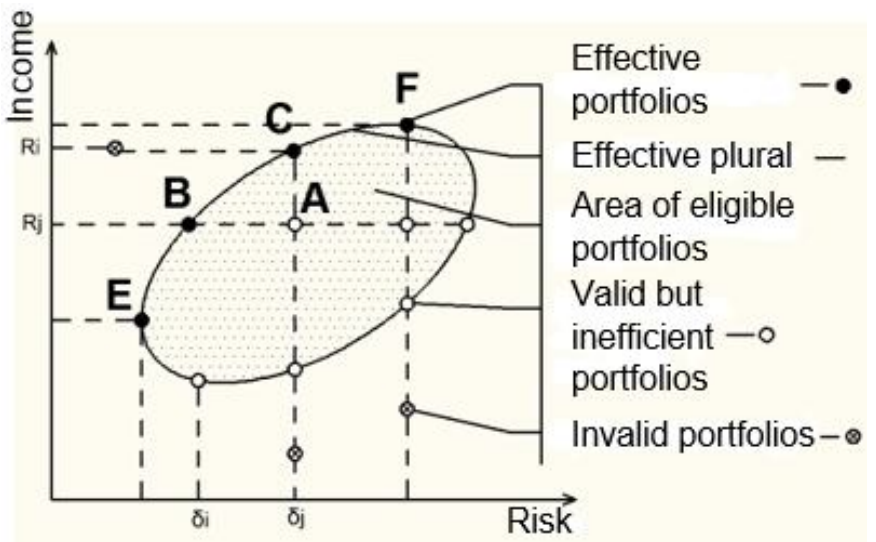

Figure 4: Modified Portfolio Markowitz model for enterprises-developers in construction

To construct the space of possible portfolios, Harry Markowitz proposed to use the class of assets, the vector of their average expected returns and the matrix of covariance. Based on these data, many possible portfolios with different profitability-risk ratios are built. Since the analysis is based on two criteria, the manager chooses portfolios:

a) or finding effective or unimproved solutions. In this case, any other solution better found on one parameter will definitely be worse than another parameter;

b) or choosing the main criterion (for example, profitability should not be below a certain value) using others only as criterion restrictions;

c) or specifying some supercriteria that is a superposition of these two (for example, their function).

To effectively manage the production program of the project portfolio should be built management system, regulated business processes that allow you to quickly assess the effectiveness of the project portfolio and make the necessary management decisions to reduce risk and maximize the profitability of the project portfolio.

It should be borne in mind that each EDC has certain limitations: financial, resource, time, and so on. As all these constraints intersect in a multi-project project portfolio, the EDC team needs to use tools and methods to ensure that the project portfolio is managed in compliance with the constraint requirements.

To select the most cost-effective version of the portfolio of future projects (orders and self-selected projects) of the development organization in the most general case can be used optimization model, which maximizes the profitability of the organization, subject to certain restrictions. It is best if the criterion of profitability is the net discounted income for each potential development project. But in this case, when assessing the effectiveness of the developer's project portfolio, it is necessary to already have design estimates for each project, which will not be economically feasible in all cases, as the cost of designing rejected projects will not be justified.

As limitations in such model can be:

- restrictions on the timing of individual projects;

- limit values of the developer's own investments in the 
Galyna Ryzhakova et al., International Journal of Emerging Trends in Engineering Research, 8(10), October 2020, 7560 - 7567

implementation of all projects accepted for implementation;

- payback periods for individual projects;

- acceptable values of social and economic indicators for individual projects;

- permissible values of consumption of some material resources for individual specific projects.

In addition to these limitations, other, but also the listed values of the limitations in the model of optimization of the developer's order portfolio can be used in full.

The objective function of the model is described as follows:

$$
D=\sum_{i}^{n} D_{i} \rightarrow \max ,(i=1,2, \ldots, n)
$$

Constraints on the model presented by the following system:

$$
\left.\begin{array}{l}
\boldsymbol{I}_{\text {own }}=\sum_{i}^{n} \boldsymbol{I}_{\text {own }} \leq \boldsymbol{I}_{\text {limit }} \\
\boldsymbol{P}=\sum_{i}^{n} \boldsymbol{P}_{i} \leq \boldsymbol{P}_{\text {ilimit }} \\
\boldsymbol{O}_{\text {environ }} \leq \sum_{i}^{n} \boldsymbol{O}_{\text {ienviron_limit }}
\end{array}\right\}
$$

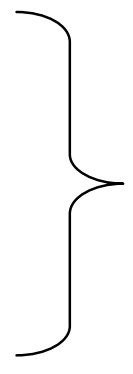

where $\boldsymbol{D}$ is profit for the entire block of the developer's project portfolio, which is essentially determined by the amount of income accepted for use projects $\left(\boldsymbol{D}_{\boldsymbol{i}}\right)$, which must be calculated as net discounted income;

$\boldsymbol{I}_{\text {own }}$ is the developer's own investments, which represent the amount of investment in each project $(\mathrm{P})$, which does not exceed the $\boldsymbol{I}_{\text {limit }}$ threshold for all projects accepted for implementation of the developer's portfolio;

$\boldsymbol{P}$ is limit for an individual material resource, which is determined by the amount of individual projects $\left(P_{i}\right)$ and should not exceed the limit value of all indicators for this resource $\left(\boldsymbol{P}_{\text {ilimit }}\right)$;

$\boldsymbol{O}_{\text {environ }}$ is environmental restrictions;

$\sum_{i}^{n} \boldsymbol{O}_{\text {ienviron_limit }}$ is environmental limitations for all projects.

To enter data on net discounted income into the model for each project, it is necessary to have design and estimate documentation, using the data of which it will be possible to calculate both indicators of net discounted income and indicators on restrictions. However, the processing of any project before the completion of the design and estimate documentation involves costs that account for about $15 \%$ of the total cost of the estimate. And the exclusion of any project at this stage will cost the developer dearly.

In addition, experimental calculations using this model have led to the belief that the error in the calculation is $10-20 \%$, as even in the presence of working documentation is not possible to obtain all the necessary source documentation for calculations. Therefore, it is proposed to choose the rational structure of the portfolio of development projects planned for implementation at the pre-project stage of the investment cycle of each development project, which is again included in the developer's portfolio.

\section{RESULTS AND DISCUSSION}

There are the results of the application to confirm the effectiveness of the proposed methodology on a practical example. To do this, three of the possible limitations of the model are given and several factors are identified that indicate the limitations of the application of the above model.

In this case, when evaluating the developer's portfolio, it includes projects that are already under implementation and for which there is already necessary and fairly reliable source information. But since in development organizations, as well as in other organizations implementing investment projects, the load on the order according to official statistics is 3-6 months, the assessment of the choice of the best structure of the order portfolio has to be done 2-3 times a year.

In such cases, it is proposed to use a simpler option for choosing a portfolio of developers' orders, namely is the use of the Board method. This method allows you to rank projects by performance indicators in the order in which they are assigned the appropriate rank values for each project. The proposed methodology proposes to improve this system by entering the values of the weight of each of the indicators taken into account.

In the most general case, when assessing the significance for the example of only four projects (A B C D) for the five most important indicators that characterize the effectiveness of projects in the portfolio of developers' orders, in table 1 shows the structure of indicators and their weight.

Table 1: The structure of ranking indicators and their importance for the four projects (A B C D)

\begin{tabular}{|c|c|c|c|c|c|}
\hline \multirow{2}{*}{ Project } & \multicolumn{5}{|c|}{ Ranks by indicators and their weight } \\
\cline { 2 - 6 } & $\boldsymbol{P}$ & $\boldsymbol{C}$ & $\boldsymbol{I}$ & $\boldsymbol{R}$ & $\boldsymbol{T}$ \\
\hline $\mathrm{A}$ & $P_{A} V_{P}$ & $C_{A} V_{C}$ & $I_{A} V_{I}$ & $R_{A} V_{R}$ & $T_{A} V_{T}$ \\
\hline $\mathrm{B}$ & $P_{B} V_{P}$ & $C_{B} V_{C}$ & $I_{B} V_{I}$ & $R_{B} V_{R}$ & $T_{B} V_{T}$ \\
\hline $\mathrm{C}$ & $P_{C} V_{P}$ & $C_{C} V_{C}$ & $I_{C} V_{I}$ & $R_{C} V_{R}$ & $T_{C} V_{T}$ \\
\hline $\mathrm{D}$ & $P_{D} V_{P}$ & $C_{D} V_{C}$ & $I_{D} V_{I}$ & $R_{D} V_{R}$ & $T_{D} V_{T}$ \\
\hline
\end{tabular}

Marking:

- indicator $\mathbf{P}$ is Profit on the project;

- indicator $\mathbf{C}$ is the duration of the investment $\mathbf{C y c l e}$;

- indicator I is the need for own Investment;

- indicator $\mathbf{R}$ is level of Risk;

- indicator $\mathbf{T}$ is payback Time's period;

$\boldsymbol{V}_{P}, \boldsymbol{V}_{\boldsymbol{C}}, \boldsymbol{V}_{I}, \boldsymbol{V}_{\boldsymbol{R}}, \boldsymbol{V}_{T}$ are weights according to the indicators taken into account.

A positive aspect in the use of this method to choose the structure of the ordering portfolio of the development organization is that for the selection of data when calculating the ranks of individual projects it is not necessary to have a fairly accurate source data. There is no need to have design and estimate documentation for all projects during such an assessment. 
In this case, it is enough to have data on the feasibility study and rapid assessment of the effectiveness of the projects, which is carried out at the earliest stage of development of each project.

The weight of evaluation indicators is set either by the developers of the portfolio structure of the development organization, or by a number of experts specially involved in this work. The same approach is used to establish rankings by indicators in cases where there is no calculation data.

The highest rank is assigned at a higher profit $(\boldsymbol{P})$ and at minimum values: the duration of the investment cycle $(\boldsymbol{C})$, the need for own investment $(\boldsymbol{I})$, risk $(\boldsymbol{R})$ and payback period $(\boldsymbol{T})$.

In the final choice of the structure of the ordering portfolio of the development organization, it is necessary to take into account one significant limitation, namely is the amount of need for own investment for all projects accepted for implementation should not exceed some threshold. Of course, in this case, a way out can be found - to go on the path of borrowing (credits, etc.), but in this case there may be a limitation associated with reducing the profitability of the organization.

To test the method of selection (optimization) of the order portfolio of the development organization using the improved Board's method, we conducted experimental calculations to substantiate the optimal order portfolio of the current developer for one calculation period in 2019, which are given below.

\section{Initial data}

1. To generate the data needed to select the best portfolio structure, an existing development organization was selected, which at the beginning of the settlement period (early 2019) had one unfinished project and four new potentially acceptable projects. Under the conditions of information confidentiality, the name of the developer is not given. Only one of the new projects was a draft project (similar to the feasibility study), and the other three were only a rapid assessment of the investment proposal, which was performed by employees of the development organization.

2. As evaluation indicators, which were used to determine the ranks of the projects, were adopted: profit $(\mathbf{P})$, duration of the investment cycle $(\mathbf{C})$, the need for own investment $(\mathbf{I})$, the level of risk $(\mathbf{R})$, payback period $(\mathbf{T})$. These are the ones that have already been listed in table 1 .

3. Employees who evaluate the order book of the organization were accepted the following weights (specific weights) of evaluation indicators (\%):

- project profit $(\mathbf{P})$ is 35 ;

- duration of the investment cycle (C) is 20;

- need for own investments (I) is 20;

- risk level $(\mathbf{R})$ is 10 ;

- payback period (T) is 15 .

4. Introduced in the calculation (under the first number) ranks of indicators for the already implemented project (under construction), along with the other four other projects are subject to accounting, although the project in all cases remains in the order book of developers.

5. As a limitation in the formation of the portfolio of orders of the development organization may be the growth of the management staff of the development organization, if the total number planned for projects will be such that a corresponding increase in permanent and (or) specialists in the management staff is unjustified.

\section{Calculation of indicators and analysis of results}

Employees who select the optimal portfolio of the development organization using the design and estimate documentation is already executed, data on the potential project, for which a preliminary design has already been developed, and some initial information from the rapid analysis of three other project proposals, as well as using external opinions experts, established ranks on the estimated indicators of all five projects (in table 2).

Table 2: Ranks on the estimated indicators of the developer's project portfolio

\begin{tabular}{|c|c|c|c|c|c|}
\hline \multirow{2}{*}{$\begin{array}{c}\text { Project } \\
\text { number }\end{array}$} & \multicolumn{5}{|c|}{ Indicator } \\
\cline { 2 - 6 } & $\boldsymbol{P}$ & $\boldsymbol{C}$ & $\boldsymbol{I}$ & $\boldsymbol{R}$ & $\boldsymbol{T}$ \\
\hline 1 & 1 & 3 & 4 & 5 & 5 \\
\hline 2 & 4 & 1 & 5 & 4 & 1 \\
\hline 3 & 3 & 5 & 3 & 3 & 4 \\
\hline 4 & 2 & 4 & 4 & 2 & 3 \\
\hline 5 & 5 & 2 & 1 & 1 & 2 \\
\hline
\end{tabular}

Taking into account the already accepted weights of individual indicators in table 3 shows the final values of the ranks of development projects accepted for consideration, which could potentially be included in the portfolio of the development organization. The weight of the indicators in the calculation was taken in fractions of a unit.

Table 3: Ranks of potentially included projects in the developer's portfolio, taking into account the importance of individual indicators

\begin{tabular}{|c|c|c|c|c|c|c|}
\hline \multirow{2}{*}{$\begin{array}{c}\text { Project } \\
\text { number }\end{array}$} & \multicolumn{5}{|c|}{ Indicator } & \multirow{2}{*}{$\begin{array}{c}\text { The sum } \\
\text { of ranks }\end{array}$} \\
\cline { 2 - 6 } & $\boldsymbol{P}$ & $\boldsymbol{C}$ & $\boldsymbol{I}$ & $\boldsymbol{R}$ & $\boldsymbol{T}$ & \\
\hline 1 & 0,35 & 0,6 & 0,8 & 0,5 & 0,75 & 3,0 \\
\hline 2 & 1,4 & 0,2 & 1,0 & 0,4 & 0,15 & 3,15 \\
\hline 3 & 1,05 & 1,0 & 0,6 & 0,3 & 0,6 & 3,55 \\
\hline 4 & 0,7 & 0,8 & 0,8 & 0,2 & 0,45 & 2,95 \\
\hline 5 & 1,75 & 0,4 & 0,2 & 0,1 & 0,3 & 2,75 \\
\hline
\end{tabular}

In the last planning period, the development organization implemented two projects. Therefore, according to the organization's management, it would be undesirable to accept five projects at once, as it is necessary to more than double the number of permanent qualified managers in the management staff, and to do so hastily was not possible. In addition, there was another limitation is the amount of cash own investment resources. It was less than the sum of the required initial equity investments for all five potential development projects. Therefore, it was necessary to reduce the number of projects implemented in the planning period by one unit. 
According to the calculation given in table 3, the decision to exclude from the project included in the portfolio of implemented the project №5. But after analyzing the work on projects №4 and №5, it was decided not to implement the project №4, as project №5 includes simpler for the developer work on the reconstruction of the existing capital facility. The performed version of the calculations to optimize the order structure of the development organization essentially confirmed the feasibility and efficiency of the proposed methodology when applying the improved Board's method in addressing the rationalization of the portfolio structure of the development organization.

\section{RESULTS AND DISCUSSION}

It should be noted that the developed methodology is the starting point for the formation of a portfolio management system for EDC development projects. According to the chosen EDC strategy, the main target indicators are approved, taking into account the stage of EDC development, business model, market trends, as well as a number of other factors, such indicators may include: financial stability ratios, the level of financial leverage of EDC, liquidity ratios, profitability ratios. Based on the formulated strategy, goals and objectives of the EDC, the requirements for the EDC are formulated, and, accordingly, the project selection criteria are established. Among the known methodological approaches, very few of them pay attention to the role of external processes in the enterprise-developer in construction, and focus mainly on internal processes and their reengineering. There may be problems at the stage of implementation of the reengineering, when the system of internal processes can be balanced, but this system will not be able to adapt to the external market environment due to separation from real market processes. Therefore, it should be noted the significant role of monitoring external processes in their applied reengineering tools for enterprises-developers in construction.

\section{REFERENCES}

1. D. Ryzhakov, O. Dikiy, M. Druzhynin, H. Petrenko and T. Savchuk. Innovative tools for management the lifecycle of strategic objectives of the enterprise-stakeholder in construction, International Journal on Emerging Trends in Engineering Research, 8(8), 2020, pp. 4526-4532, https://doi.org/10.30534/ijeter/2020/78882020

2. D. Chernyshev, D.Ryzhakov, O. Dikiy, O. Khomenko and S.Petrukha. Innovative Technology for Management Tools of Commercial Real Estate in Construction, International Journal on Emerging Trends in Engineering Research, 8(9), September 2020, pp. 4967-4973, https://doi.org/10.30534/ijeter/2020/13892020

3. J. Marchuk, D Ryzhakov, G. Ryzhakova, S. Stetsenko. Identification of the basic elements of the innovation-analytical platform for energy efficiency in project financing, Investment Management and Financial Innovations, Volume 14, Issue 4, 2017, pp. 12-20, http://dx.doi.org/10.21511/imfi.14(4).2017.02
4. P Kulikov, M. Dyomin, D. Chernyshev, D. Kuśnierz-Krupa and $M$. Krupa. The issues of preservation and revitalization of residential, public and industrial buildings from the second half of the 19th and early 20th centuries in Kyiv and Krakow, Wiadomosci Konserwatorskie, Vol. 2019, Issue 60, 2019, pp. 140-146.

5. Y. Ivashko, D. Chernyshev and P. Chang. Functional and figurative and compositional features of traditional Chinese pavilions, Wiadomosci Konserwatorskie, Vol. 2020, Issue 61, 2020, pp. 60-66.

6. M. Dyomin, A. Dmytrenko, D. Chernyshev and Y. Ivashko. Big Cities Industrial Territories Revitalization Problems and Ways of Their Solution, Lecture Notes in Civil Engineering, Vol.73, 2020, pp. 365-373.

7. V. Mihaylenko, T. Honcharenko, K. Chupryna, Yu. Andrashko and S. Budnik. Modeling of Spatial Data on the Construction Site Based on Multidimensional Information Objects. International Journal of Engineering and Advanced Technology.Volume-8 Issue-6, pp.3934-3940, August 2019. URL: https://www.ijeat.org/wp-content/uploads/papers/v8i6/F 9057088619.pdf

8. T. Honcharenko, Y. Chupryna, I. Ivakhnenko, M. Zinchenco, T. Tsyfra. Reengineering of the Construction Companies Based on BIM-technology, International Journal of Emerging Trends in Engineering Research, 8(8), August 2020, pp. 4166-4172 https://doi.org/10.30534/ijeter/2020/22882020

9. O. Terentyev, S. Tsiutsiura, T. Honcharenko and T. Lyashchenko. Multidimensional Space Structure for Adaptable Data Model, International Journal of Recent Technology and Engineering (IJRTE), Volume-8 Issue-3, pp. 7753-7758, September 2019. URL: https://www.ijrte.org/wp-content/uploads/papers/v8i3/C 6318098319.pdf

10. M. Ahmad, T. Sinelnikova, S. Mustafa, V.Lyashenko. Features of the Construction and Control of the Navigation System of a Mobile Robot. International Journal on Emerging Trends in Engineering Research, 8(4), pp. 1445-1449, April 2020. https://doi.org/10.30534/ijeter/2020/82842020

11. C. Y. Lin, M. Wu, J. A. Bloom, I. J. Cox, and M. Miller. Rotation, scale, and translation resilient public watermarking for images, IEEE Trans. Image Process., vol. 10, no. 5, pp. 767-782, May 2001.

12. T. Ishchenko, Yu. Chupryna, V. Pokolenko. The organization of biosphere compatibility construction: justification of the predictors of building development and the implementation prospects, International Journal of Engineering \& Technology, 7(3.2), 2018, pp. 545-549.

13. V. Savchenko, V. Akhramovych, A.Tushych, I. Sribna, I. Vlasov. Analysis of Social Network Parameters and the Likelihood of its Construction. International Journal on Emerging Trends in Engineering Research, 8(2), pp. 271-276, April 2020, https://doi.org/10.30534/ijeter/2020/05822020 
14. I. Ulbieva, K.Uzhakhov, A.Tsechoeva, A.Dzangieva, M.Uzhakhov. The Construction Technology of Preschool Institutions: Eco-Friendly and Fire-Resistant Materials, International Journal on Emerging Trends in Engineering Research, 8(4), April 2020, Pages 1227-1231, https://doi.org/10.30534/ijeter/2020/46842020

15. I. Kulikov, K. Karpukhin. Studying Energy Efficiency of Thermal Management Systems Designed for Electric Vehicles with In-Wheel Motors, International Journal on Emerging Trends in Engineering Research, 8(6), June 2020, pp. 2654-2662, https://doi.org/10.30534/ijeter/2020/ 71862020

16. O. O. Gorshkova. Construction of Long-Distance Oil Pipelines, International Journal on Emerging Trends in Engineering Research, 8(1), January 2020, pp. 60-66, https://doi.org/10.30534/ijeter/2020/11812020

17. H. Elbardan, A. Othman, R. Kholeif. Enterprise Resource Planning, Corporate Governance and Internal Auditing. An Institutional Perspective, Cham: Palgrave Macmillan, 2017. 446 p. doi: http://doi.org/10.1007/978-3-319-54990-3

18. S. Kortmann. The Relationship between Organizational Structure and Organizational Ambidexterity. A Comparison between Manufacturing and Service Firm, Springer Gabler, 2012. 183 p. http://doi.org/10.1007/978-3-8349-3630-1

19. T. Janssen. Enterprise Engineering. Sustained Improvement of Organizations. Cham: Springer, 2016,148 p. doi: http://doi.org/10.1007/978-3319-24172-2

20. Miller R., Strombom D., Iammarino M., Black B. The commercial real estate revolution: nine transforming keys to lowering costs, cutting waste, and driving change in a broken industry, John Wiley \& Sons, 2009. $352 \mathrm{p}$.

21. Y. Riabchun, T. Honcharenko, V. Honta, K. Chupryna, O. Fedusenko. Methods and means of evaluation and development for prospective students' spatial awareness in International Journal of Innovative Technology and Exploring Engineering, Volume 8, Issue 11, September 2019, Pages 4050-4058, https://www.ijitee.org/wp-content/uploads/papers/v8i11/ K15320981119.pdf

22. F. Heidari, P. Loucopoulos. Quality evaluation framework (QEF): Modeling and evaluating quality of business processes in International Journal of Accounting Information Systems, 15 (3), 2014, pp.193-223.

23. S. Appel, P. Kleber, S. Frischbier, T. Freudenreich, A. Buchmann, Modeling and execution of event stream processing in business processes, Information Systems, 46, 2014, pp. 140-156.

24. Doing Business (2020). URL: https://www.doingbusiness.org/en/data

25. M. E. Mangram, A simplified perspective of the Markowitz portfolio theory. Global journal of business research, 7(1), 58-70, 2013. 